\title{
Physiological manipulation of cellular activity tunes protein and ultrastructural profiles in a neuroendocrine cell
}

\author{
François van Herp, Nick H M van Bakel, Anton J M Coenen, Kjell Sergeant ${ }^{1}$, Bart Devreese ${ }^{2}$ \\ and Gerard J M Martens \\ Department of Molecular Animal Physiology, Faculty of Science, Donders Center for Neuroscience, Nijmegen Center for Molecular Life Sciences (NCMLS), \\ Radboud University, Geert Grooteplein Zuid 28, 6525 GA Nijmegen, The Netherlands \\ ${ }^{1}$ Department of Environment and Agrobiotechnologies, Centre de Recherche Public-Gabriel Lippmann, L-4422 Belvaux, Luxembourg \\ ${ }^{2}$ Laboratory of Protein Biochemistry and Biomolecular Engineering, Ghent University, B-9000 Ghent, Belgium \\ (Correspondence should be addressed to F van Herp; Email: f.vanherp@ncmls.ru.nl)
}

\begin{abstract}
To study in vivo the dynamics of the biosynthetic and secretory processes in a neuroendocrine cell, we use the proopiomelanocortin-producing intermediate pituitary melanotrope cells of Xenopus laevis. The activity of these cells can be simply manipulated by adapting the animal to a white or a black background, resulting in inactive and hyperactive cells respectively. Here, we applied differential display proteomics and field emission scanning electron microscopy (FESEM) to examine the changes in architecture accompanying the gradual transition of the inactive to the hyperactive melanotrope cells.
\end{abstract}

The proteomic analysis showed differential expression of neuroendocrine secretory proteins, endoplasmic reticulum (ER)-resident chaperones, and housekeeping and metabolic proteins. The FESEM study revealed changes in the ultrastructure of the ER and Golgi and the number of secretory granules. We conclude that activation of neuroendocrine cells tunes their molecular machineries and organelles to become professional secretors.

Journal of Endocrinology (2008) 198, 607-616

\section{Introduction}

In eukaryotic cells, the endoplasmic reticulum (ER) and Golgi apparatus play a pivotal role in the quality control of secretory proteins. The ER contains enzymes and molecular chaperones ensuring that secretory proteins are folded and assembled to achieve their correct tertiary structures, whereas the Golgi controls a number of post-translational modifications and the sorting event. In the secretory granules of neuronal and endocrine cells, prohormones are proteolytically cleaved to biologically active peptides. Our model system, the proopiomelanocortin (Pomc)-producing intermediate pituitary melanotrope cells of Xenopus laevis, is ideal to study the quality control of synthesis and transport of secretory proteins in physiologically inactive and activated neuroendocrine cells. The model concerns a well-characterized physiological neuroendocrine reflex, namely skin color change as a result of adaptation to a changed background condition. By placing the animal on a black background, the melanotrope cells are triggered to produce and release $\alpha$-melanophore stimulating hormone $(\alpha-M S H)$ that stimulates the dispersion of melanin in the melanophores of the skin, causing a darkening of the animal. An elevated release of $\boldsymbol{\alpha}-\mathrm{MSH}$ is accompanied by a high expression rate of Pomc, the prohormone for $\alpha-\mathrm{MSH}$. Consequently, melanotrope cells of black-background-adapted Xenopi contain $\sim 30$ times more Pomc mRNA and display a much higher biosynthetic and secretory activity than those of whitebackground-adapted animals (Jenks et al. 1993). The $37 \mathrm{kDa}$ precursor form of POMC is processed to the intermediate $\mathrm{N}$-terminal $18 \mathrm{kDa}$ cleavage fragment and a number of peptides, including $\alpha$-MSH. The prohormone convertase 2 (PC2) plays a primary role in the proteolytic processing of POMC (e.g. Braks et al. 1992) and occurs in an inactive proenzyme form and an enzymatically active form. Following activation through an autocatalytic reaction, active PC2 cleaves the prohormone at pairs of basic amino acid residues (e.g. Benjannet et al. 1991).

Earlier studies have focused on the extreme situations, namely on the inactive melanotrope cells in fully whitebackground-adapted Xenopus and on the hyperactive cells of animals fully adapted to a black background. In the inactive and hyperactive Xenopus melanotrope cells, differential expression has been found for a number of gene transcripts encoding proteins involved in prohormone biosynthesis (Holthuis et al. 1995) and protein expression of POMC and a number of ER chaperones (Devreese et al. 2002). Cytological differences in the inactive and hyperactive cells have been studied by transmission electron microscopy (TEM; Hopkins 1970, de Rijk et al. 1990), a morphometric 
TEM approach (Weatherhead \& Whur 1972) and field emission scanning electron microscopy (FESEM; Van Herp et al. 2005). The latter technique provides a fast and detailed 3D survey of organelles.

Here, we decided to use differential display proteomics and FESEM to study the dynamics of the melanotrope cell model by examining the protein and ultrastructural patterns not only in melanotrope cells from fully white- and fully blackbackground-adapted Xenopus, but also from white animals periodically adapted to a black background and thus with various states of cellular activity. The combination of the two methods permitted us to compare the molecular and cellular events in inactive, gradually activated and hyperactive Xenopus melanotrope cells.

\section{Materials and Methods}

\section{Chemicals}

The chemicals for the buffer solutions were purchased from Merck. The chemicals specifically used for the proteomics study were: Tris base (from Invitrogen), Pefablock (Roche), trichloroacetic acid, diethyl ether, ethanol, sodium thiosulfate, formaldehyde and EDTA (from Merck), deoxycholate, thiourea, CHAPS (3-cholamidopropyl dimethylamino-1-propanesulphonate), 1,4-dithiothreitol and iodoacetamide (from Sigma-Aldrich), urea and glutaraldehyde (from Fluka, Sigma-Aldrich), SDS (from LKB, Bromma, Sweden), acrylamide/bisacrylamide (from MP Biochemicals, Solon, OH, USA), and acetic acid (from Acros Organics, Geel, Belgium). Chemicals specifically for the FESEM method were: glutaraldehyde (25\% solution (from Agar Scientific, Stansted, UK), 1-hexadecene (from Merck), and gold-palladium (from Cressington Scientific Instruments Ltd, Watford, UK).

Preparation of Xenopus melanotrope cells under different physiologically (hyper)active situations

South African claw-toed frogs X. laevis were bred, reared, and maintained in the Central Animal Facility of the Radboud University (Nijmegen, The Netherlands). All animal experiments were carried out in accordance with the European Communities Council Directive 86/609/EEC for animal welfare and the RU-DEC 2003-53 and 2007-027 from the animal experiment committee of the Radboud University for enabling the use of $X$. laevis frogs. Animals adapted to a grey background were put on a white or a black background for various time periods to obtain melanotrope cells with different degrees of (hyper)activity, namely 1) inactive melanotrope cells: longer than 3 weeks adaptation of grey-background-adapted animals to a white background; 2) short-term-activated melanotrope cells: 6,12 , and 24 h (1 day) adaptation of whitebackground-adapted animals to a black background and 3) longterm-activated melanotrope cells: 2, 3, 6, 12, and 24 days adaptation of white-background-adapted animals to a black background. The virtually inactive melanotrope cells of longterm white-adapted animals were used as a reference point for cellular inactivity. A number of animals were adapted for the indicated time points and a selection between these animals was made using the melanophore index (i.e. melanosome aggregation in the skin; white: 1; black: 5). For the differential display proteomics approach, we used three animals per time point, while for the FESEM approach at each time point the number of animals varied between three and five depending on the quality of the sample preparation.

\section{Identification of proteins in the melanotrope cells of $\mathrm{X}$. laevis}

The identification of the protein spots selected for our proteomics study was performed by a combination of $2 \mathrm{D}$ electrophoresis and mass spectrometry, and details of the approach have been described by Devreese et al. (2002). The protein spots were cut from the gel and subjected to in-gel protein digestion followed by mass spectrometric characterization. All spots were submitted to MALDI TOF/TOF analysis. For spots for which MALDI-MS(/MS) did not provide a significant hit, we used the automated nanoLC-MS-MS system (Devreese et al. 2002). Mascot was used for protein identification using the non-redundant NCBI database. For some protein spots, the Xenopus EST database embedded in the NCBI databases was interrogated.

\section{Differential display proteomics}

Sample preparation and protein extraction Each dissected Xenopus neurointermediate lobe was collected in a glass/glass potter. Homogenization was performed in $250 \mu \mathrm{l}$ of a solution containing $40 \mathrm{mM}$ Tris base $(\mathrm{pH} 9.5)$ and $10 \mathrm{mM}$ Pefablock. The proteins were precipitated by a trichloroacetic acid-deoxycholate (TCA-DOC) procedure based on the method described by Molloy et al. (1998). The homogenized sample was adjusted to $900 \mu \mathrm{l}$ with ice-cooled $10 \mathrm{mM}$ PBS (pH 7·4), mixed by vortex with $100 \mu \mathrm{l}$ icecooled 3\% DOC, and incubated for $30 \mathrm{~min}$ on ice. Then, $110 \mu 1$ 100\% TCA was added, mixed, and left on ice for $15 \mathrm{~min}$ and then centrifuged at $21000 \mathrm{~g}$ at $4{ }^{\circ} \mathrm{C}$. The precipitated material was washed in $1 \mathrm{ml}$ diethyl etherethanol (1:1), thoroughly mixed (by vortex) and centrifuged again at $21000 \mathrm{~g}$ for $20 \mathrm{~min}$. After three further washing steps, the recuperated precipitate was air dried for about $2 \mathrm{~h}$. The dry material was then dissolved in $50 \mu \mathrm{l}$ lysis buffer containing $7 \mathrm{M}$ urea, $2 \mathrm{M}$ thiourea, 4\% CHAPS, 1\% 1,4dithiothreitol (DTT), and 0.8\% IPGphor buffer (pH 3-10L) and sonicated three times for 5 seconds on ice-cooled water.

Two-dimensional gel electrophoresis The 2D gel electrophoretic analysis was performed on an immobilized $\mathrm{pH}$ gradient (IPGPhor) system and the SDS-PAGE (Ettan DALT six) electrophoresis unit (Amersham-Bioscience). For electrophoresis in the first dimension, each premade IPG drystrip 
(18 cm, pH 3-10L) was placed in the porcelain electrophoretic holder containing the $50 \mu \mathrm{l}$ sample and $310 \mu \mathrm{l}$ rehydration buffer (8 M urea, 0.5\% CHAPS, 0.5\% IPGphor (pH 3-10L), $0 \cdot 28 \%$ DTT, and $5 \mu \mathrm{l}$ bromophenol blue solution $(1 \mathrm{mg} / \mathrm{ml})$, which was primarily centrifuged for $15 \mathrm{~min}$ at $1000 \mathrm{~g}$ at room temperature). The strips were then covered with IPGphor cover fluid and put under an electric field of $50 \mu \mathrm{A}$ per strip at $20^{\circ} \mathrm{C}$. Further rehydration/separation took place at $30 \mathrm{~V}$ for $12 \mathrm{~h}$ $(360 \mathrm{Vh}), 500 \mathrm{~V}$ and $1000 \mathrm{~V}$ each for $1 \mathrm{~h}$ (respectively 500 and $1000 \mathrm{Vh})$, and $8000 \mathrm{~V}$ for $4 \frac{1}{2} \mathrm{~h}(36000 \mathrm{Vh})$. After this electrofocusing step, the strips were washed for a few seconds in distilled water and prepared for the second electrophoretic run by incubation under shaking for $15 \mathrm{~min}$ in equilibration buffer (6 M urea, 30\% (w/v) glycerol, and 2\% (w/v) SDS dissolved in 0.05 M Tris-HCl buffer ( $\mathrm{pH} 8 \cdot 8)$ ), containing $2 \mu \mathrm{l}$ bromophenol blue and $10 \mathrm{mg}$ DTT per $\mathrm{ml}$ equilibration buffer, and $15 \mathrm{~min}$ in equilibration buffer containing $25 \mathrm{mg}$ iodoacetamide per $\mathrm{ml}$. Then, they were dried on filter paper and placed on a self-made $12.5 \%$ SDS-PAGE gel $(25$ by $21 \mathrm{~cm})$ to separate the proteins according to their molecular weight. After the second electrophoretic run, the SDS-PAGE gels were fixed during $30 \mathrm{~min}$ in fixation solution $(40 \mathrm{ml}$ ethanol, $10 \mathrm{ml}$ acetic acid, and $50 \mathrm{ml}$ distilled water) and silver stained according to the following standardized procedure: $30 \mathrm{~min}$ in sensitization solution (30 ml ethanol, $292 \mu$ glutaraldehyde, $4 \mathrm{ml} 5 \%$ sodium thiosulfate, $6.8 \mathrm{~g}$ sodium acetate, and $66 \mathrm{ml}$ distilled water), three times $5 \mathrm{~min}$ washing in distilled water, $20 \mathrm{~min}$ in staining solution (100 $\mathrm{ml}$ distilled water, $40 \mu \mathrm{l}$ formaldehyde, and $0 \cdot 25 \mathrm{~g}$ $\mathrm{AgNO}_{3}$ ), twice rinsing for exactly $1 \mathrm{~min}$ each in distilled water, exactly $4 \mathrm{~min}$ in developing solution $\left(6.74 \mathrm{~g} \mathrm{Na}_{2} \mathrm{CO}_{3} 10 \mathrm{H}_{2} \mathrm{O}\right.$, $20 \mu \mathrm{l}$ formaldehyde in $100 \mathrm{ml}$ distilled water), and finally rinsing for $10 \mathrm{~min}$ in EDTA solution (1.42 g EDTA in $100 \mathrm{ml}$ distilled water) and for $10 \mathrm{~min}$ in distilled water.

Analysis of differentially expressed proteins For analyzing the differential expression of the selected proteins (see Table 1 and Fig. 2), we used the electropherograms of three individual neurointermediate lobes for each time point. The relative amounts of the selected proteins were measured by densitometric scanning of the gels using the Umax Powerlook III (Amersham). Spot detection and matching of spots between gels was performed with the PDQuest software package (version 7.2 of Bio-Rad). Normalization between the gels was based on the total signal of specific melanotrope cell spots (i.e., total protein amount) per gel and all scanned gels were corrected for background signals. Quantification of each protein family was based on the total sum of the selected protein spots. The statistical evaluation of the relative changes was carried out using the program SPSS (version 12.0.1; Chicago, IL, USA). To test homogeneity of variances, we used Levene statistics, when appropriate, $\log$ transformation was performed. The expression profile data of PC2, immunoglobulin heavy chain-binding protein or $76 \mathrm{kDa}$ glucose-regulated protein precursor $(\mathrm{BiP})$, calreticulin, protein disulfide isomerase (PDI), $90 \mathrm{kDa}$ heat shock protein (HSP90), actin, enolase, and aldolase were analyzed using one-way ANOVA followed by post hoc analysis with Dunnett $t$ (two-sided). Since no homogeneity of variance was reached after log transformation for the expression profiles of POMC $37 \mathrm{kDa}$, POMC $18 \mathrm{kDa}$, and glyceraldehyde-3phosphate dehydrogenase (GAPDH), Kruskal-Wallis followed by Mann-Whitney $U$ tests were used for statistical analysis.

\section{FESEM}

To explore the time course of the ultrastructural changes during the transition from one activity state of the melanotrope cells to another state, we applied the fast cryoFESEM approach described by Van Herp et al. (2005). Following dissection of the pituitary and separation of the pars intermedia from the pars nervosa, a tissue consisting predominantly of melanotrope cells was obtained. Each preparation was immediately fixed in $0.5 \%$ glutaraldehyde (prepared in $0 \cdot 1 \mathrm{M}$ cacodylate buffer, $\mathrm{pH} 7 \cdot 4$ ) for $1 \mathrm{~h}$, three times rinsed in cacodylate buffer for $30 \mathrm{~min}$ each, and

Table 1 Protein identification in the melanotrope cells of Xenopus laevis

\begin{tabular}{|c|c|c|c|c|}
\hline & Protein name & NCBI acc. no. & Mr kDa (theor.) & pl (theor.) \\
\hline \multicolumn{5}{|l|}{ Protein family } \\
\hline \multirow{3}{*}{ Regulated secretory proteins } & 37 kDa POMC & gi|5931776 & $29 \cdot 9$ & $6 \cdot 2$ \\
\hline & 18 kDa POMC & - & $12 \cdot 6$ & $4 \cdot 8$ \\
\hline & PC2 & gi|64972 & $70 \cdot 5$ & $5 \cdot 6$ \\
\hline \multirow[t]{3}{*}{ ER-resident proteins } & $\mathrm{BiP}$ & gi|27370850 & $72 \cdot 3$ & $5 \cdot 0$ \\
\hline & Calreticulin & gi|64609 & $48 \cdot 3$ & $4 \cdot 4$ \\
\hline & PDI & gi|28302197 & $56 \cdot 6$ & $5 \cdot 6$ \\
\hline \multirow[t]{5}{*}{ Housekeeping and metabolic proteins } & $\beta$-Actin & gi|537596 & $41 \cdot 8$ & $5 \cdot 3$ \\
\hline & GAPDH & gi|24415375 & $35 \cdot 9$ & $8 \cdot 5$ \\
\hline & $\alpha$-Enolase & gi|32450571 & $47 \cdot 4$ & $6 \cdot 2$ \\
\hline & Aldolase & gi|1944025 & $39 \cdot 4$ & $8 \cdot 5$ \\
\hline & HSP90 & gi|27803582 & $82 \cdot 9$ & $5 \cdot 0$ \\
\hline
\end{tabular}

$\mathrm{BiP}$, immunoglobulin heavy chain-binding protein or $76 \mathrm{kDa}$ glucose-regulated protein precursor; GAPDH, glyceraldehyde-3-phosphate dehydrogenase; HSP90, $90 \mathrm{kDa}$ heat shock protein; PC2, prohormone convertase 2; PDI, protein disulfide isomerase; $37 \mathrm{~K} \mathrm{POMC} \mathrm{(ProPOMC),} \mathrm{precursor} \mathrm{of}$ proopiomelanocortin; $18 \mathrm{~K} \mathrm{POMC}$, processed form of POMC. Details of the identification are given in Supplementary Tables 1 and 2 , see Supplementary data in the online of version of the Journal of Endocrinology at http://joe.endocrinology-journals.org/content/vol198/issue3/. 
incubated in $30 \%$ glycerol/cacodylate buffer for at least $1 \mathrm{~h}$. After this light fixation step, each sample was mounted in 1-hexadecene into the cavity of a cylindrical carrier (Oxford; $3 \mathrm{~mm} \times 1.4 \mathrm{~mm}$ outer diameter and $1 \mathrm{~mm}$ inner diameter) leaving a part of the tissue free on top of the tube and 'slush' cryofixed in liquid nitrogen. The obtained fragile frozen sample was then mounted on a sample holder of the freezefracturing device from Oxford Alto and immediately transferred to the Alto 2500 cryo-preparation chamber using the vacuum transfer device for fracturing, etching, and coating of the samples. All tissue samples were fractured at $-120^{\circ} \mathrm{C}$, etched for $3 \mathrm{~min}$ at $-95^{\circ} \mathrm{C}$, coated with a $2-3 \mathrm{~nm}$ layer of gold-palladium, and subsequently transferred to the high vacuum area of a coupled JEOL 6330 FESEM microscope. The results of the FESEM observations were analyzed after processing and archiving of the images on a computer.

\section{Results}

Dynamics of the protein expression profiles in Xenopus melanotrope cells with different states of activity

To examine the changes in protein expression during the gradual transition of the inactive to the hyperactive Xenopus melanotrope cells, we selected a number of proteins that we have previously found to be differentially expressed in fully white- and fully black-background-adapted animals (Table 1 and Fig. 1A; Devreese et al. 2002). As we were primarily interested in protein processing, folding, maturation, and trafficking in the melanotrope cells, we used regulated secretory proteins (37 kDa POMC, $18 \mathrm{kDa}$ POMC, and PC2) to follow the processing activity in the cells and ER-resident proteins (BiP, calreticulin an PDI) to examine the folding and maturation activity in the luminal part of the ER. The housekeeping ( $\beta$-actin) and metabolic (GAPDH, $\alpha$-enolase, and aldolase) proteins were selected to obtain information on the status of the cytoskeleton and the basal energy metabolism respectively. With HSP90, we wanted to follow protein-folding activity in the cytoplasm. An overview of the changes in protein expression levels of the selected family members at the various time points is shown in Fig. 1B. Together, these proteins allowed us to follow the quality control of the biosynthetic and secretory activities of the melanotrope cells in white animals adapting to a black background.

Figure 2, showing the endocrine response during blackbackground adaptation, provides the protein expression profiles of the POMC precursor $(37 \mathrm{kDa})$ and the cleaved $18 \mathrm{kDa}$ form of POMC as well as of the PC2 (the precursor and mature forms of this POMC cleavage enzyme). Significantly, higher amounts of $37 \mathrm{kDa}$ POMC were measured only after 12 days of black-background adaptation $(P<0 \cdot 05)$. In contrast, the processed $18 \mathrm{kDa}$ form of POMC showed similar amounts during the whole adaptation period. The amounts of PC2 were the highest in white-adapted animals and gradually decreased in the first week of blackbackground adaptation. During the longer adaptation periods, the level of PC2 increased again but remained 2.5 times lower than in fully white-adapted animals. At all time points examined, the various levels of $18 \mathrm{kDa}$ POMC expression were not significantly different nor were those of PC2 expression.

As components of the ER play an essential role in the proper folding and maturation of newly synthesized proteins in the secretory pathway, we followed in the melanotrope cells the changes in the levels of the ER-resident proteins BiP, calreticulin, and PDI during black-background adaptation of the animal (Fig. 3). After normalization of the density of the corresponding protein spots in the 2D electropherograms (Fig. 1), we found that the relative amounts of the three selected proteins remained low up to the third day of adaptation to a black background. However, the levels of BiP, calreticulin, and PDI increased gradually when the cells became activated by longer adaption of the animals to a black background. The amounts of the ER chaperones present in the hyperactive melanotrope cells, when the animals were adapted for 2-3 weeks, were significantly different from those in the inactive cells $(\mathrm{BiP}(P<0 \cdot 005)$, calreticulin $(P<0 \cdot 05)$, and PDI $(P<0 \cdot 005)$.

To obtain insight into their structural and metabolic states during activation of the melanotrope cells, we selected the following housekeeping proteins: actin as a marker for the cytoskeletal changes, GAPDH, enolase, and aldolase for the metabolic changes and HSP90 for the changes in cytoplasmic folding activity (Fig. 4). In contrast to the proteins involved in folding and maturation of newly synthesized proteins (Fig. 3), no clear trend was observed for the proteins involved in housekeeping functions. The relative amount of actin was constant during the time period examined. Relatively large changes in the relative amounts of the GAPDH, enolase, and aldolase proteins were observed during the adaptation period, but these changes were only significantly different for enolase $(P<0 \cdot 05$ and $P<0 \cdot 01)$.

The cytosol-localized HSP90, a protein with chaperone activity, influences the regulation of transcription of a discrete set of genes. The amount of HSP90 remained low during the first week of adaptation but increased afterwards to levels that were $2 \cdot 5$ and 6 times higher after 12 and 24 days of adaptation respectively $(P<0 \cdot 005$; Fig. 4$)$. Therefore, the protein expression of HSP90 showed a trend similar to those of the chaperones operational in the secretory pathway (Fig. 3).

\section{Ultrastructural differences between physiologically inactive, gradually activated, and hyperactivated Xenopus melanotrope cells}

The cryo-FESEM method was used to allow a fast and detailed study on the biosynthetic and secretory activities in the melanotrope cells of Xenopus adapted to a white or black background for extended time series (longer than 3 weeks adapted to a white background and adapted for 6, 12, and $24 \mathrm{~h}$, and for 2, 3, 6, 12, and 24 days to a black background). 
A

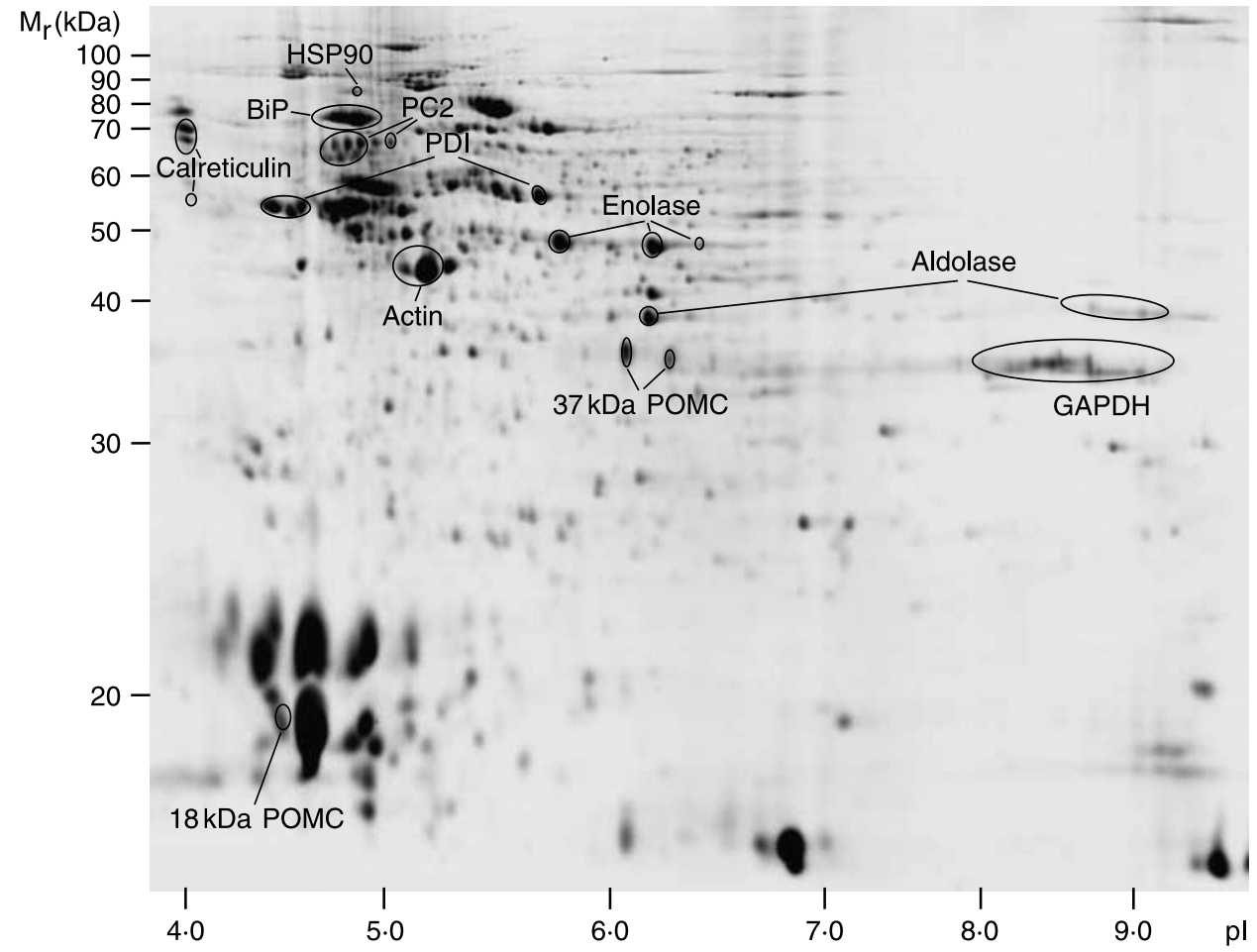

B

B Adaptation period

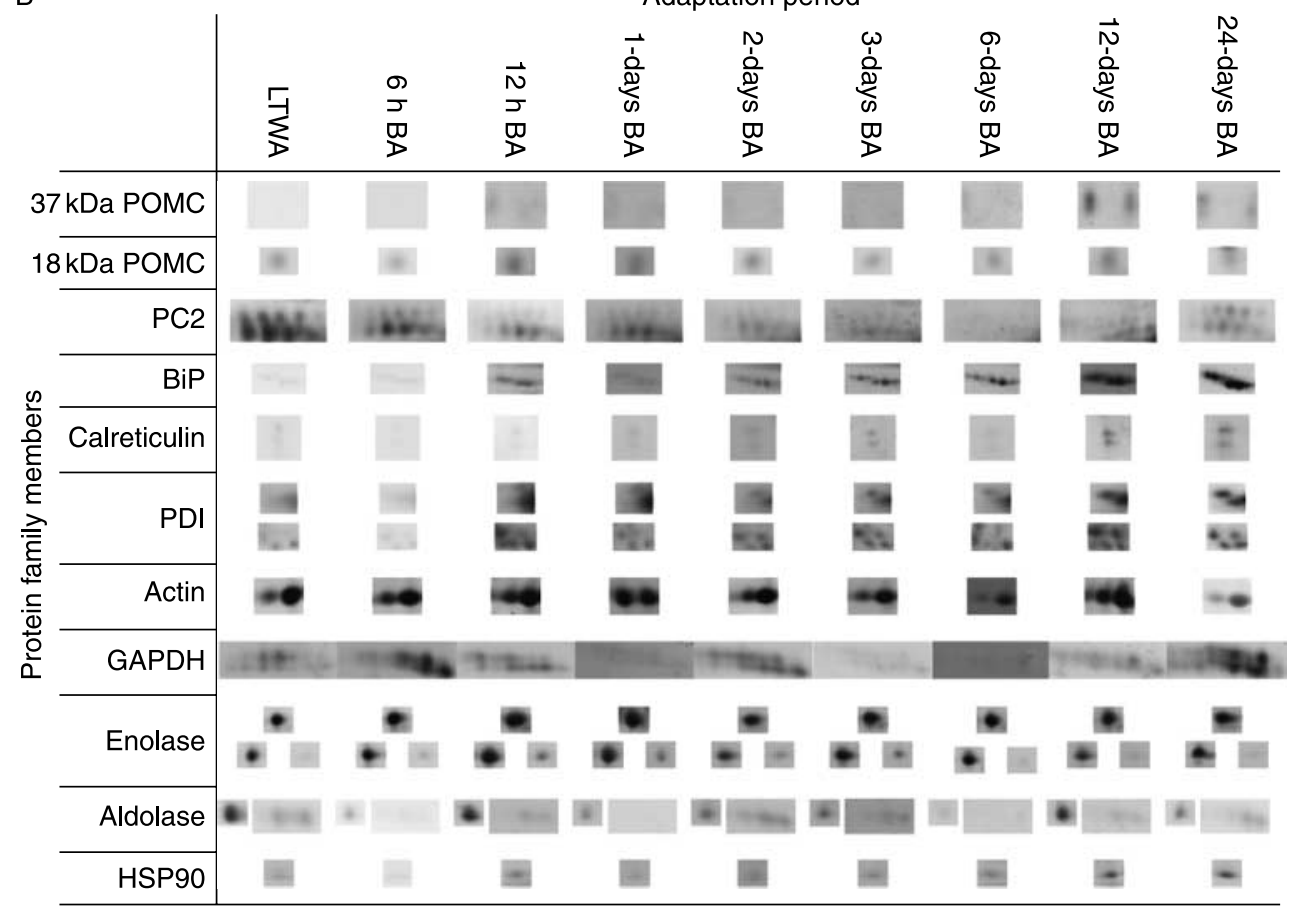

Figure 1 (A) 2D PAGE electropherogram of proteins expressed in melanotrope cells of 24-day blackbackground-adapted Xenopus. Indicated are the locations of the proteins selected for detailed analysis. (B) Overview of the changes in protein expression levels of the selected family members at various time points. 

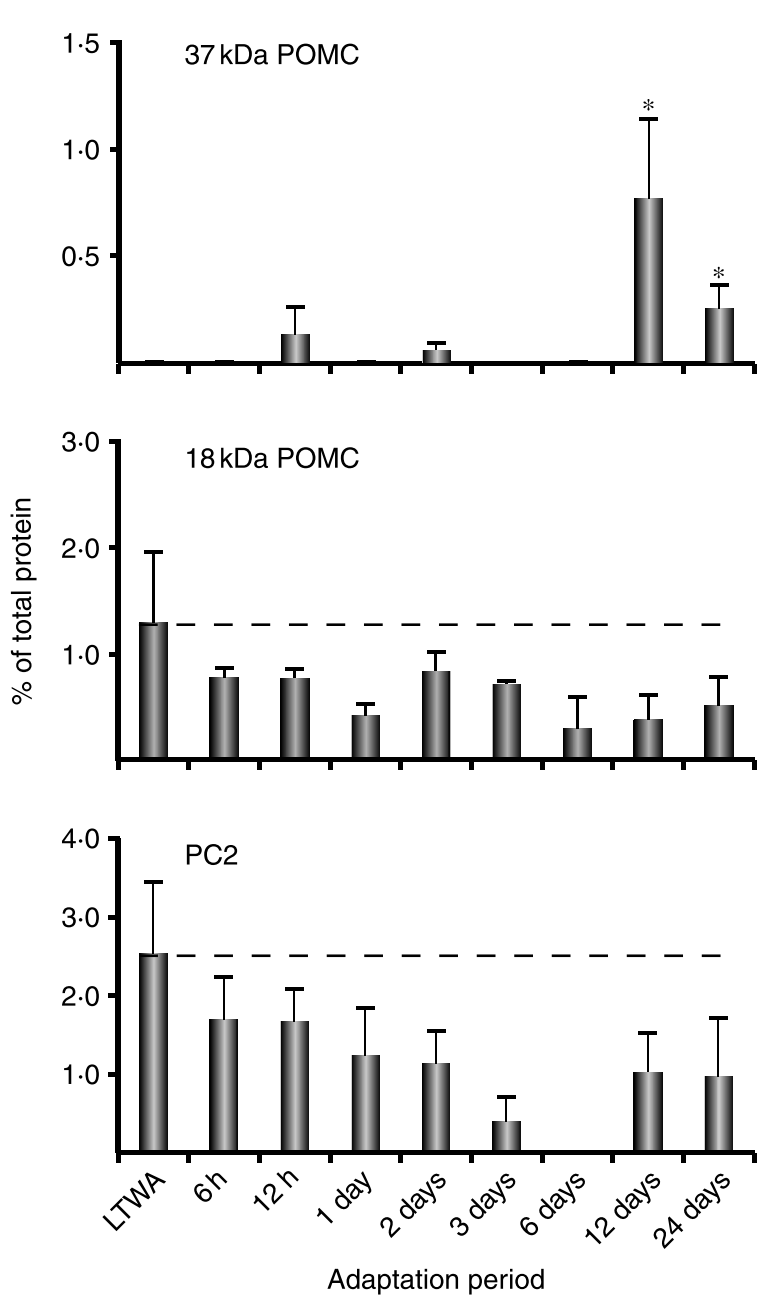

Figure 2 Quantification of relative protein amounts of 37 and $18 \mathrm{kDa}$ POMC and PC2 in the melanotrope cells of Xenopus during short- and long-term adaptation to a black background (values are expressed as the mean +S.E.M.; $n=3$ individual protein samples each analyzed on a separate gel; $* P<0 \cdot 05$ different from the values of long-term white-adapted (LTWA) animals). The dotted line indicates the expression level in inactive melanotrope cells.

After fracturing of the high-pressure-frozen melanotrope cells, the fracture plane was frequently found in regions containing ER and secretory granules, and the nucleus was mostly flatly broken or fractured through the region of the nuclear envelope. The quality of the ultrastructural analysis was such that the cytoplasmic microstructures were readily visible in the finely granulated cytosolic matrix (Fig. 5A-H). The ultrastructural information obtained could therefore be directly combined with the described molecular information.

The population of inactive melanotrope cells from whiteadapted Xenopus, studied at low and high magnifications, was dense and no or only a few intercellular spaces were found with most of the cells being round to oval and completely loaded with round to oval granules. In the inactive cells, the ER and Golgi were poorly developed (Fig. 5A).
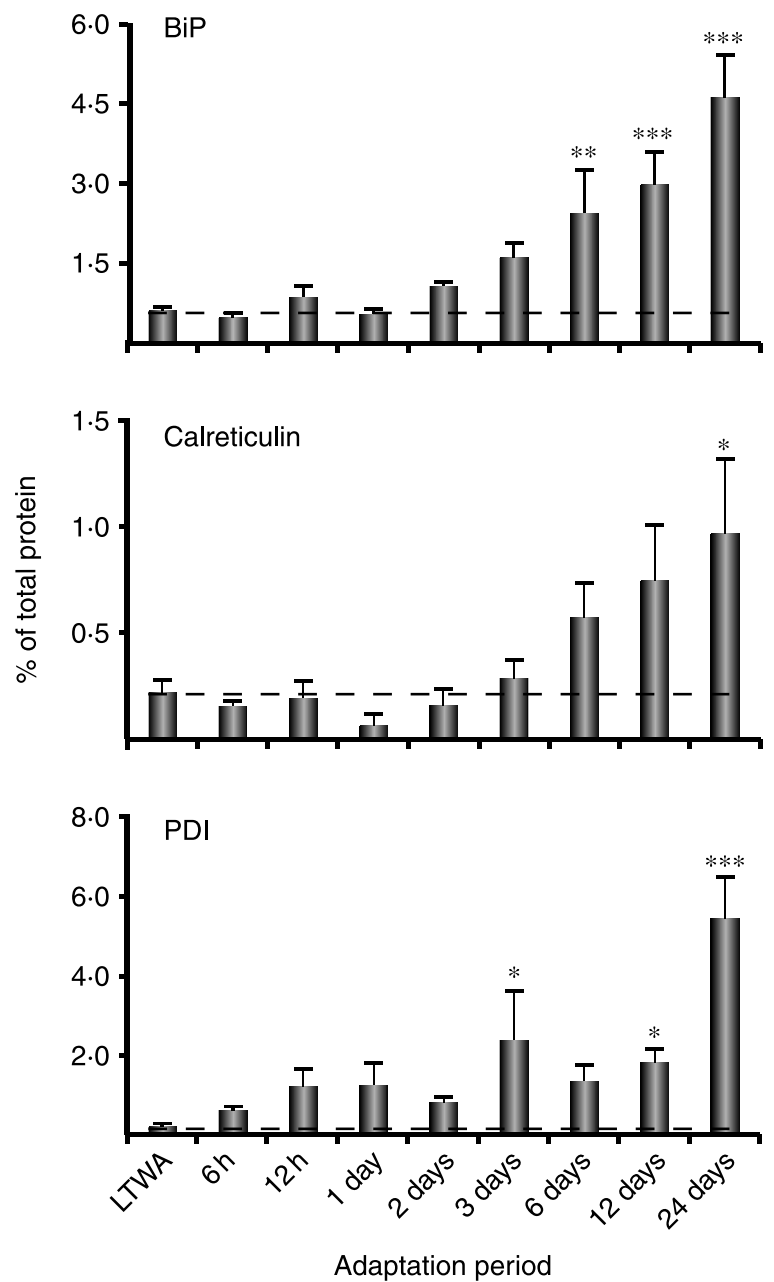

Figure 3 Quantification of relative protein amounts of $\mathrm{BiP}$, calreticulin, and PDI in melanotrope cells of Xenopus during short- and long-term adaptation to a black background (values are expressed as the mean +S.E.M.; $n=3$ individual protein samples each analyzed on a separate gel; ${ }^{*} P<0 \cdot 05 ;{ }^{*} P<0 \cdot 01$ and $* * * P<0.005$ different from the values of long-term white-adapted (LTWA) animals). The dotted line indicates the expression level in inactive melanotrope cells.

In white-adapted animals adapted to a black background for 6 or $12 \mathrm{~h}$, the melanotrope cells showed their first cytological changes in that the density of the secretory granules decreased (Fig. 5B) and the cells started to become elongate (Fig. 5C). In this short-term adaptation period, the cells became activated and started to release the contents of their storage granules. The melanotrope cells of 24-h blackbackground-adapted exhibited a remarkable organelle reorganization in that the number of granules was gradually reduced and larger vesicular structures were present in the cytoplasm of the activated cells (Fig. 5D).

Characteristics of cellular activation became visible following adaptation of the animal for a longer time period. Around the second day, tubular structures of the ER surrounding the nuclei 

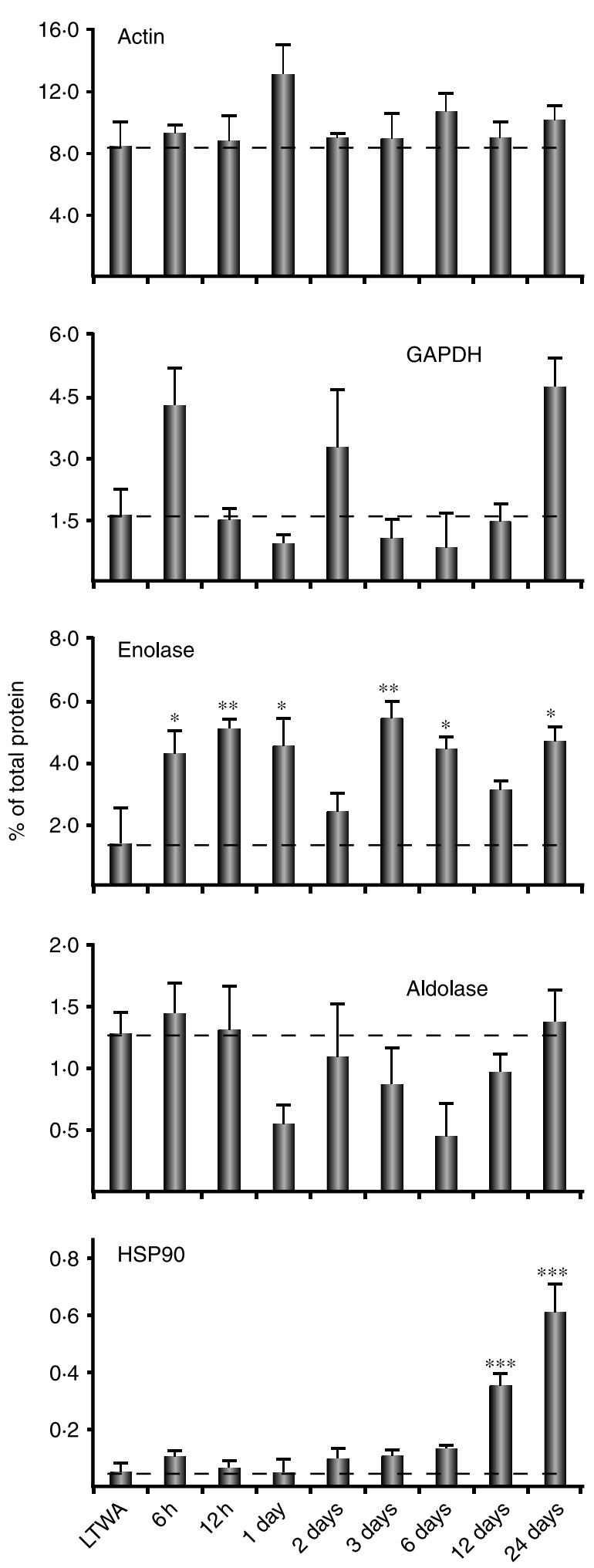

Adaptation period of the melanotrope cells became visible and the amounts of ER and Golgi gradually increased (Fig. 5E). Between 3 and 6 days of adaptation, fenestrated saccule/tubular networks of the Golgi apparatus, surrounded by cysternae of rough ER, were frequently observed in the melanotrope cells (Fig. 5F). The number of active melanotrope cells gradually increased between 6 and 12 days of black-background adaptation and, after 24 days, all cells were hyperactivated and contained high levels of ER and Golgi activities. In these fully black-background-adapted animals (24 days), the hyperactive melanotrope cells were present as a loosely attached group of elongated cells and the cytoplasm of these cells was filled with rough ER and contained only a low number of secretory granules (Fig. 5G) and welldeveloped Golgi (Fig. 5H).

\section{Discussion}

Dynamics of the protein expression profiles in Xenopus melanotrope cells with different activity states

One of the main focuses of this study was an analysis of the protein expression patterns of 37 and $18 \mathrm{kDa}$ POMC and of the proteolytic cleavage enzyme PC2. Our data indicate that the $18 \mathrm{kDa}$ cleaved form of POMC and not the $37 \mathrm{kDa}$ precursor is the major storage product in the melanotrope cells of animals adapted to a white background. During the adaptation period the levels of this cleaved form remained similar, while only after a prolonged adaptation to a black background the cellular amount of $37 \mathrm{kDa}$ POMC started to increase. These results are in line with the Western blot data previously described by Dotman et al. (1998). During the adaptation period, the expression profiles of $18 \mathrm{kDA}$ POMC and PC2 showed a similar tendency. Coexpression of POMC and the PC2 genes has been described at the mRNA level in X. laevis (Martens et al. 1987, Braks et al. 1992, Holthuis et al. 1995) and in Rana ridibunda (Peinado et al. 2006). In white frogs, the melanotrope cells are loaded with storage products $(18 \mathrm{kDa}$ form of POMC and PC2) and, once triggered, the cells are ready to rapidly release the stored material. When the cells are activated, the cellular level of $18 \mathrm{kDa}$ POMC decreases due to a higher rate of secretion. The newly synthesized $37 \mathrm{kDa}$ POMC molecules are rapidly cleaved by PC2 and only after long-term black-background adaptation the amount of the $37 \mathrm{kDa}$ prohormone increases to detectable levels.

The expression of the ER chaperones is increased in the activated cells and is very high in the hyperactive cells when the cells exhibit markedly increased biosynthetic and

Figure 4 Quantification of relative protein amounts of actin, GAPDH, enolase, aldolase, and HSP90 in melanotrope cells of Xenopus during short- and long-term adaptation to a black background (values are expressed as the mean +S.E.M.; $n=3$ individual protein samples each analyzed on a separate gel; $* P<0 \cdot 05 ;{ }^{* * P}<0.01$ and ${ }^{* * *} P<0.005$ different from the values of long-term white-adapted (LTWA) animals). The dotted line indicates the expression level in inactive melanotrope cells. 

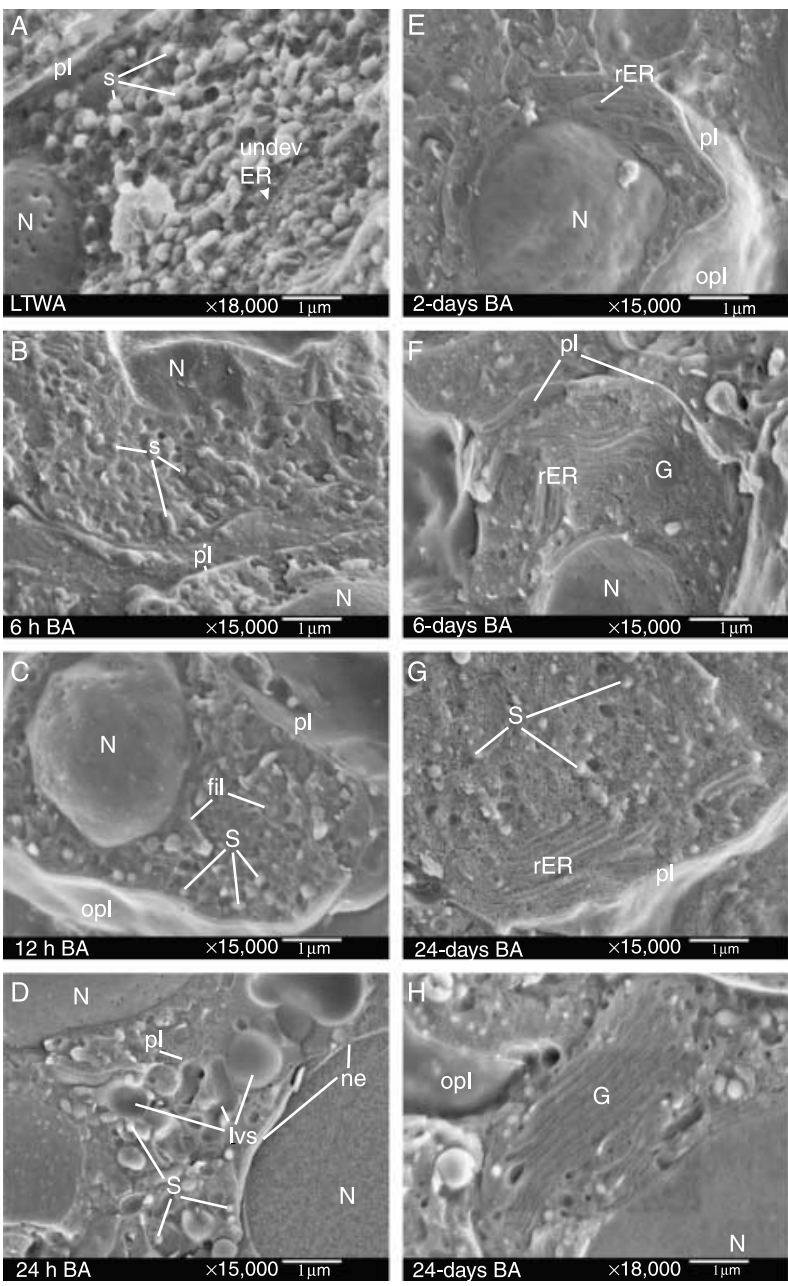

Figure $5(\mathrm{~A}-\mathrm{H})$ FESEM observations. (A) FESEM at high magnification of an inactive melanotrope cells of a fully white-background-adapted Xenopus. Bar, $1 \mu \mathrm{m}$. (B-D) FESEM at high magnification showing melanotrope cells of Xenopus after shortterm adaptation to a black background (B, $6 \mathrm{~h} ; \mathrm{C}, 12 \mathrm{~h}$; and D, $24 \mathrm{~h})$. Bar, $1 \mu \mathrm{m}$. (E-F) FESEM at high magnification showing melanotrope cells of Xenopus after long-term adaptation to a black background ( $E, 2$ days; F, 6 days). Bar, $1 \mu \mathrm{m}$. (G-H) FESEM at high magnification of hyperactive melanotrope cells of a fully blackbackground-adapted Xenopus (24 days adaptation to a black background). Bar, $1 \mu \mathrm{m}$. fil, filament-like structures forming a matrix around the secretory granules; G, some cysternae of the Golgi complex; Ivs, large vesicular structure; $N$, nucleus; ne, nuclear envelope; opl, outer side of the plasma membrane; pl, plasma membrane; rER, well-developed rough endoplasmic reticulum; $s$, secretory granule; undev ER, poorly developed ER.

secretory activities characterized by a high level of POMC biosynthesis, and $\alpha-\mathrm{MSH}$ acetylation and release as shown by Jenks et al. (1993) and Vàsquez-Martinez et al. (2005). Since ER chaperones play a role in protein folding, facilitate the assembly of multimeric protein complexes or participate in the folding of proteins containing disulfide bonds (Benham \& Braakman 2000, Ellgaard \& Helenius 2001, Schröder \& Kaufman 2005), the higher expression of BiP, calreticulin, and
PDI in long-term black-background-adapted animals reflects their key function in POMC biosynthesis and the generation of the final secretory peptide signals under (hyper)activated conditions.

The housekeeping proteins actin, GAPDH, enolase, and aldolase were selected to provide an insight into the metabolic activity of the cells. These proteins are not directly involved in secretory pathway processes, but actin is an important protein in the cytoskeleton, and GADPH, aldolase, and enolase are key enzymes in energy metabolism. Although the melanotrope cells changed their activity from an inactive to a hyperactive state during the adaptation period, the amount of actin remained about the same. The variations in the levels of the metabolic enzymes may reflect fluctuations in the metabolic activities of the melanotrope cells under various states of activity and may thus represent biological sample variations.

The changes in HSP90 protein levels were comparable with the differences in expression of the ER-resident proteins, illustrating a functional link between this heat shock protein and the ER folding catalysts.

Ultrastructural differences between physiologically inactive, gradually activated, and hyperactivated Xenopus melanotrope cells

We recently applied FESEM to study the ultrastructural differences in the inactive and hyperactive Xenopus melanotrope cells (Van Herp et al. 2005). These results were similar to the TEM ultrastructural data described by Hopkins (1970), Weatherhead \& Whur (1972) and de Rijk et al. (1990). Now we have extended our cryo-FESEM observations with the description of the ultrastructural changes in melanotrope cells under various states of cellular activity. A drawback of the freeze-fracturing procedure, being part of the FESEM technique, is the fact that flat block faces are created on which only a limited number of fractured areas of high quality can be obtained. For this reason, morphometric measurements on a high number of equally sectioned cells were not possible, and we thus studied the differences on a broad series of samples to confirm the reproducibility of the ultrastructural characteristics for each activity state. We found that the melanotrope cells of white-adapted animals are in a secretory inactive state, containing numerous storage granules and poorly developed Golgi and ER, that the cells are activated during a short-term adaption of the white Xenopi to a black background and that the cells become hyperactive and have large amounts of rough ER and a well-developed Golgi in a long-term black-background-adapted situation. In fully white-background-adapted animals, the far majority of the melanotrope cells were inactive, whereas most melanotrope cells in fully black-background-adapted animals were in a hyperactive state. These observations are in line with earlier morphometric TEM observations showing that nearly all melanotrope cells (95\%) of white-background-adapted Xenopus animals are inactive and that about $80 \%$ of the 
melanotropes in black-background-adapted animals are hyperactive (de Rijk et al. 1990).

Intriguingly, the drastic reorganization that we observed following $24 \mathrm{~h}$ of black-background adaptation has not been previously found. Hopkins (1970) detected one or two multivesicular bodies in the melanotrope cells of fully whiteadapted animals. We, however, found high numbers of multivesicular bodies in cells of animal adapted for $24 \mathrm{~h}$. The significance of these multivesicular bodies is at present unclear. The presence of the bodies may be related to the formation of the peripheral cisternae of the Golgi complex, and their contents may be comparable with the contents in the cisternal complex of the Golgi (Hopkins 1970). Alternatively, the large multivesicular structures may be linked to the formation of lysosomal bodies recycling membranous material that is present following the high levels of release of the storage granular content at the beginning of black-background adaptation.

Biological relevance of the dynamics in protein and ultrastructural patterns of Xenopus melanotrope cells with different cellular activity states

The combination of differential display proteomics and FESEM enabled us to compare the molecular and cellular events in inactive, physiologically activated, and hyperactive melanotrope cells of $X$. laevis. The inactive melanotrope cells are characterized by a high density of storage granules and a poorly developed ER and Golgi; their secretory activity and the level of POMC is low, but their hormonal content in the storage granules is high. In this situation, the amounts of the processed $18 \mathrm{kDa}$ POMC form and of the POMC-processing enzyme PC2 are high, whereas the amounts of the $37 \mathrm{kDa}$ POMC precursor form and of the ER chaperones and HSP90 are low. The biosynthetic and secretory activities of the melanotrope cells are induced when the animals adapt to a black background. The first ultrastructural changes are observed already after a short adaptation period, namely after 6-12 h of adaptation the density of the secretory granules in the cells was reduced and after $24 \mathrm{~h}$ a dramatic cytological reorganization occurred. The induction of the release process at $24 \mathrm{~h}$ is reflected by the reduced amounts of $18 \mathrm{kDa}$ POMC and PC2. On the second day of black-background adaptation, ER laminar structures become visible and, between 3 and 6 days of black-background adaptation, these structures gradually develop in more and more cells. During that period, the amounts of BiP, calreticulin, and PDI increase significantly. Following an adaptation period of 12-24 days, the biosynthetic and secretory activities greatly increase in all melanotrope cells of black-background-adapted animals. The activated cells are filled with large amounts of rough ER and well-developed Golgi structures are frequently seen. At the protein expression level, the hyperactivity is first obvious after 12 days, namely the presence of a high amount of the $37 \mathrm{kDa}$ precursor form of POMC. The need for folding and maturation of the precursor is reflected by the high levels of the ER chaperones BiP, calreticulin, and PDI. Thus, the reorganization of the organelles is accompanied by differences in the expression patterns of the selected protein families and the tuning of the processes is relatively slow.

Despite the cytological changes, the levels of expression of the housekeeping and metabolic proteins remained remarkably the same. For instance, the shape of the melanotrope cells and the density of the cell population changed from oval/round cells at a high density in white-backgroundadapted animals to elongated cells at a lower density in blackbackground-adapted animals, while the amounts of actin were similar. The fact that the protein expression profiles of the metabolic enzymes were not significantly different in inactive and activated cells indicates that these enzymes are important for general melanotrope cell functioning.

In conclusion, the combination of differential display proteomics and FESEM allowed us to link the differences in expression of various protein family members with the changes in the architecture of the Xenopus melanotrope cells, illustrating that neuroendocrine cells tune their protein and ultrastructural patterns such that they become professional secretors.

\section{Declaration of interest}

The authors declare there is no conflict of interest which would prejudice the impartiality of this scientific work.

\section{Funding}

This work was supported by the Radboud University, Nijmegen and the Ghent University but did not receive any specific grant from any funding agency in the public, commercial, or not-for-profit sector.

\section{Acknowledgements}

This study is dedicated to Karel Janssen who set up and started the proteomics analysis but died unexpectedly on 17 October 2004.

\section{References}

Benham AM \& Braakman I 2000 Glycoprotein folding in the endoplasmic reticulum. Critical Reviews in Biochemistry and Molecular Biology 35 433-473. Benjannet S, Rondeau N, Day R, Chrétien M \& Seidah NG 1991 PC1 and PC2 are proprotein convertases capable of cleaving proopiomelanocortin at distinct pairs of basic residues. PNAS 88 3564-3568.

Braks JM, Guldemond KC, van Riel MCHM, Coenen AJM \& Martens GJM 1992 Structure and expression of Xenopus prohormone convertase PC2. FEBS Letters 305 45-50.

Devreese B, Janssen KPC, Vanrobaeys F, Van Herp F, Martens GM \& Van Beeumen J 2002 Automated nanoflow liquid chromatography-tandem mass spectrometry for a differential display proteomic study on Xenopus laevis neuroendocrine cells. Journal of Chromatography. A 976 113-121.

Dotman CH, Van Herp F, Martens GJM, Jenks BG \& Roubos EW 1998 Dynamics of proopiomelanocortin and prohormone convertase (PC2) gene expression in Xenopus melanotrope cells during long-term background adaptation. Journal of Endocrinology 159 281-286. 
Ellgaard L \& Helenius A 2001 ER quality control: towards an understanding at the molecular level. Current Opinion in Cell Biology 13 431-437.

Van Herp F, Coenen T, Geurts HPM, Janssen HPM \& Martens GJM 2005 A fast method to study the secretory activity of neuroendocrine cells at the ultrasructural level. Journal of Microscopy 218 79-83.

Holthuis JCM, Jansen EJR, van Riel MCHM \& Martens GJM 1995 Molecular probing of the secretory pathway in peptide hormoneproducing cells. Journal of Cell Science 108 3295-3305.

Hopkins CR 1970 Studies on secretory activity in the pars intermedia of Xenopus laevis 1 . Fine structural changes related to the onset of secretory activity in vivo. Tissue and Cell 2 59-70.

Jenks BG, Leenders HJ, Martens GJM \& Roubos EW 1993 Adaptation physiology: the functioning of pituitary melanotrope cells during background adaptation of the amphibian Xenopus laevis. Zoological Science $\mathbf{1 0}$ $1-11$.

Martens GJM, Weterings KAP, van Zoest ID \& Jenks BG 1987 Physiologically-induced changes in proopiomelanocortin mRNA levels in the pituitary of the amphibian Xenopus laevis. Biochemical and Biophysical Research Communications 143 678-684.

Molloy MP, Herbert BR, Walsh BJ, Tyler MI, Traini M, Sanchez J-C, Hochstrasser DF, Williams KL \& Gooley AA 1998 Extraction of membrane proteins by differential solubilization for separation using two-dimensional gel electrophoresis. Electrophoresis 19 837-844.

Peinado JR, Cruz-García D, Vásquez-Matínez R, Anouar Y, Tonon MC, Vaudry H, Gracia-Navarro F, Castaño JP \& Malagón MM 2006 RT-PCR analysis of the expression of POMC and its processing enzyme PC1 in amphibian melanotropes. General and Comparative Endocrinology 147 222-230.

de Rijk EPCT, Jenks BG \& Wendelaar Bonga SE 1990 Morphology of the pars intermedia and the melanotrope stimulating cells in Xenopus laevis in relation to background adaptation. General and Comparative Endocrinology 79 74-82.

Schröder M \& Kaufman RJ 2005 ER stress and unfolded protein response. Mutation Research 569 29-63.

Vàzquez-Martínez R, Peinado JR, Cruz-García D, Ruiz-Navarro A, GraciaNavarro F, Anouar Y, Tonon MC, Vaudry H, Castaño JP \& Malagón MM 2005 Melanotrope cells as a model to understand the (patho)physiological regulation of hormone secretion. Journal of Endocrinological Investigation $\mathbf{2 8}$ 949-958.

Weatherhead B \& Whur P 1972 Quantification of ultrastructural changes in the melanotrope-stimulating hormone cell of the pars intermedia of Xenopus laevis, produced by change of background color. Journal of Endocrinology 53 303-310.

Received in final form 17 June 2008

Accepted 24 June 2008

Made available online as an Accepted Preprint 24 June 2008 